\title{
Perbaikan Kemasan Kerupuk Singkong (Samiler) di UKM Karya Lestari Jaya Tulungagung
}

\author{
Dadang Hermawan ${ }^{1}$, Andy Hardianto ${ }^{2}$, Arief Rizki Fadhillah ${ }^{3}$ \\ ${ }^{1,3}$ Mesin Otomotif ${ }^{2}$ Teknik Industri, ${ }^{1,2,3}$ Fakultas Teknik, \\ ${ }_{1,2,3}$ Universitas Widyagama Malang \\ *e-mail corresponding author : ${ }^{1}$ dadang@ widyagama.ac.id, HP. 08813451248 \\ e-mail anggota : ${ }^{2}$ andyhardian@gmail.com, ${ }^{3}$ arfadris11@gmail.com
}

\begin{abstract}
ABSTRAK
Singkong atau ubikayu (Manihot esculenta Crantz) merupakan salah satu sumber karbohidrat lokal Indonesia yang menduduki urutan ketiga terbesar setelah padi dan jagung. Salah satu pemanfaatan singkong adalah kerupuk singkong (samiler). Kerupuk singkong (samiler) adalah makanan ringan yang sangat populer dikalangan masyarakat, terbuat dari singkong, berbentuk bundar tipis dan rasanya gurih. Kapasitas Produksi UKM Karya Lestari Jaya dalam memproduksi kerupuk singkong (samiler) dalam 1 hari sebanyak $\pm 20 \mathrm{~kg}$ bahan atau $5 \mathrm{~kg}$ kerupuk singkong (samiler) kering. Dalam satu bulan pesanan kerupuk singkong (samiler) dapat mencapai \pm 80-120 kg. Proses Produksi kerupuk singkong (samiler) melalui beberapa tahapan, antara lain : proses bahan baku, proses pencetakan, proses steam, proses penjemuran dan proses pengemasan. Permasalahan yang dapat diidentifikasi dalam bidang produksi adalah keterbatasan peralatan dalam proses packaging dan penimbangan kerupuk singkong samiler. Mitra UKM Karya Lestari Jaya dalam melakukan perhitungan harga produk per kemasan belum memenuhi standar break even point (BEP), sehingga tidak dapat maksimal dalam pengelolaan usaha. Dari kondisi diatas maka metode dan hasil dari pengabdian ini adalah memberikan transfer teknologi dengan memberikan Mesin vaccum sealer, continuous band sealer, dan timbangan digital serta melakukan pelatihan penggunaan alat dan pelatihan Break Even Point (BEP) sehingga meningkatkan efisiensi produksi Kerupuk singkong (samiler).
\end{abstract}

\section{Kata kunci : kerupuk singkong; mesin pengemasan; pelatihan alat; BEP}

\begin{abstract}
Cassava or cassava (Manihot esculenta Crantz) is one of Indonesia's local carbohydrate sources which ranks third largest after rice and corn. One of the uses of cassava is cassava crackers (samiler). Cassava crackers (samiler) are very popular snacks among the people, made from cassava, thin round in shape and taste delicious. Production Capacity of Karya Lestari Jaya's UKM in producing cassava crackers (samiler) in 1 day is $\pm 20 \mathrm{~kg}$ of material or $5 \mathrm{~kg}$ of dried cassava crackers (samiler). In one month cassava cracker orders (samiler) can reach $\pm 80-120 \mathrm{~kg}$. The production process of cassava crackers (samiler) goes through several stages, including: raw material process, printing process, steam process, drying process and packaging process.
\end{abstract}

Cara Mengutip : Hermawan, D., Hardianto, A., Fadhillah, A. R., (2020). Perbaikan Kemasan Kerupuk Singkong (Samiler) di UKM Karya Lestari Jaya Tulungagung. JAST : Jurnal Aplikasi Sains dan Teknologi, 4 (1), 9-17. doi:http://dx.doi.org/10.33366/jast.v4i1.1473 
cannot be maximized in business management. From the above conditions, the method and results of this service are providing technology transfer by providing vaccum sealer machines, continuous band sealers, and digital scales as well as training in the use of tools and training in Break Even Point (BEP) so as to increase production efficiency of cassava crackers (samiler).

Keywords : cassava crackers; packaging machines; training tools; BEP

\section{Pendahuluan}

Singkong atau ubikayu (Manihot esculenta Crantz) merupakan salah satu sumber karbohidrat lokal Indonesia yang menduduki urutan ketiga terbesar setelah padi dan jagung [1]. Berdasarkan data BPS Provinsi Jawa Timur tahun 2007 2016, rata-rata produksi ubi kayu/singkong mencapai $\pm 3-4$ Juta ton per tahun. Dari beberapa kota/ kabupaten di Provinsi Jawa Timur terdapat Kabupaten Tulungagung yang menjadi salah satu penghasil singkong terbesar yaitu rata-rata produksi sebesar $\pm 120-$ 180 ribu ton per tahun [2].

Salah satu pemanfaatan singkong adalah kerupuk singkong (samiler). Kerupuk singkong (samiler) adalah makanan ringan yang sangat populer dikalangan masyarakat, terbuat dari singkong, berbentuk bundar tipis dan rasanya gurih [3]. Hal ini yang telah dilakukan oleh beberapa UKM di Kabupaten Tulungagung sebagai produsen kerupuk singkong (samiler), salah satunya adalah UKM Karya Lestari Jaya. UKM ini dirintis oleh bapak Kusni Abbas yang beralamatkan di Dusun Pecuk RT 03 RW 02 Desa Pecuk, Kecamatan Pakel, Kabupaten Tulungagung - Provinsi Jawa Timur. UKM ini didirikan sejak tahun 2012 dan memiliki perkembangan yang sangat baik. Tenaga kerja pada UKM ini adalah 4 (empat) orang, dengan upah kerja upah perhari Rp. 45.000,00 / perhari. Pada gambar 1.1 adalah salah satu Sertifikat
Produksi Pangan Industri Rumah Tangga (SPP-IRT) dengan nomor P-IRT 2153504011939-19 produk kerupuk singkong (samiler) yang telah dimiliki oleh UKM. Konsumen kerupuk singkong (samiler) UKM Karya Lestari Jaya, antara lain : masyarakat umum, pekerja yang bekerja di luar negeri (TKI/TKW), dan para pemilik usaha oleh-oleh yang terdapat pada Kabupaten Tulungagung.

Kapasitas Produksi UKM Karya Lestari Jaya dalam memproduksi kerupuk singkong (samiler) dalam 1 hari sebanyak $\pm 20 \mathrm{~kg}$ bahan atau $5 \mathrm{~kg}$ kerupuk singkong (samiler) kering. Dalam satu bulan pesanan kerupuk singkong (samiler) dapat mencapai $\pm 80-120 \mathrm{~kg}$.

Proses Produksi kerupuk singkong (samiler) melalui beberapa tahapan, antara lain: proses bahan baku, proses pencetakan, proses steam, proses penjemuran dan proses pengemasan. Proses bahan baku dilakukan beberapa proses yaitu memilih singkong yang telah ditentukan standar dan mutunya, pengupasan kulit singkong, pencucian singkong yang telah dikupas, pemarutan singkong. Pemarutan singkong menggunakan mesin parut singkong dengan mesin 4 tak. Hasil dari singkong yang telah diparut dilanjutkan dengan proses penyimpanan dalam kulkas selama 2 hari sebelum dilakukan pencetakan kerupuk singkong (samiler). Proses pencetakan dilakukan beberapa proses yaitu hasil gilingan singkong yang telah 
disimpan selam 2 hari dalam kulkas, maka dilanjutkan pada tahapan pemberian bumbu dan diaduk menjadi adonan sebelum dicetak menjadi kerupuk singkong (samiler). Alat pencetakan samiler menggunakan loyang alumunium ukuran 45 x $40 \mathrm{~cm}$ dan garpu yang selanjutnya dilakukan pencetakan secara manual. Proses steam/kukus adalah proses dimana hasil cetakan samiler di kukus dengan waktu 10 menit. Pengukusan kerupuk dilakukan dengan menggunakan mesin steamer dengan 8 rak, sehingga dapat menampung 8 loyang dalam sekali proses kukus. Proses penjemuran dilakukan setelah proses kukus selesai dilakukan dengan cara melepas satu per satu kerupuk singkong (samiler) dari loyang dan diletakkan pada jaring kawat yang telah dibentuk persegi untuk selanjutnya dilakukan penjemuran. Lama waktu penjemuran dipengaruhi oleh kondisi cuaca di daerah mitra UKM. Proses packaging dilakukan pada saat kerupuk telah benar-benar kering. Berat kerupuk singkong (samiler) dalam satu kemasan memiliki beberapa variasai, antara lain : 2 ons, $1 / 4 \mathrm{~kg}, 1 / 2 \mathrm{~kg}, 1 \mathrm{~kg}$. Produk yang dihasilkan dalam oelh mitra UKM hanya kerupuk singkong (samiler) dengan rasa original. UKM dalam menimbang kerupuk singkong (samiler) menggunakan alat yang sederhana yaitu timbangan pasar / timbangan bebek. Kerupuk singkong (samiler) dijual dalam bentuk kerupuk mentah (belum digoreng). Selain itu, UKM Karya Lestari Jaya juga dapat membuat kerupuk singkong (samiler) yang telah digoreng apabila ada konsumen memesan. Kemasan yang digunakan adalah plastik kiloan.

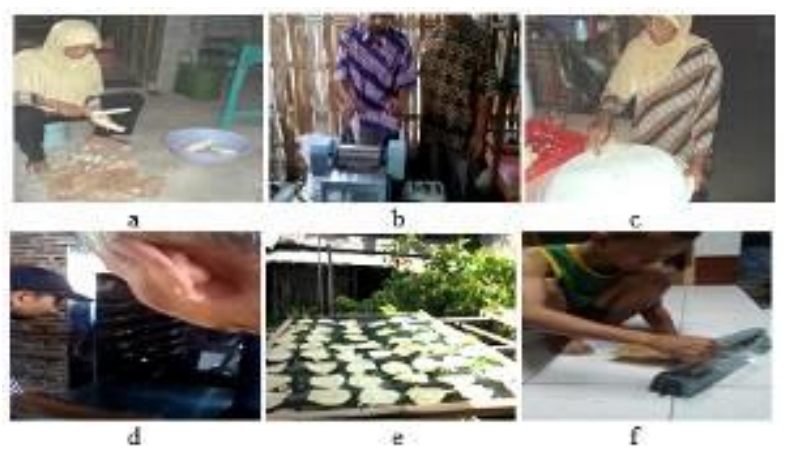

Keterangan :

a. Proses bahan baku : pengupasan dan pencucian

b. Proses pemarutan singkong

c. Proses pencetakan kerupuk singkong (samiler)

d. Proses steamer

e. Proses penjemuran

f. Proses pengemasan

Gambar 1. Proses Produksi Kerupuk Singkong (samiler)

Dalam rangka meningkatkan permintaan konsumen pada kerupuk singkong (samiler), maka perlu adanya perbaikan pada beberapa aspek, antara lain : proses packaging, kemasan yang sesuai standar, dan perluasan pemasaran melalui media iklan. Hal ini dikarenakan UKM Mitra Lestari Jaya tidak memiliki proses packaging yang baik, kemasan yang tidak standar dan pemasaran yang kurang luas.

Terhadap kondisi umum usaha, para pelaku usaha pernah mengalami berbagai macam pengalaman serta pasang surutnya usaha ini, namun mereka menyimpulkan bahwa usaha kerupuk singkong (samiler) ini dipandang sebagai usaha yang akan terus tumbuh di masa-masa yang akan datang. Hal ini bisa dilihat dari jumlah omzet dan order kerupuk singkong (samiler) mengalami peningkatan dalam empat tahun ini. Masalah dari para pelaku usaha kerupuk singkong (samiler) ini adalah tidak mampu menghasilkan 
kemasan yang menarik dan sesuai standar kemasan produk pangan.

\section{Bidang Produksi}

Permasalahan yang dapat diidentifikasi dalam bidang produksi adalah keterbatasan peralatan dalam proses packaging dan penimbangan kerupuk singkong samiler. Adapun permasalahannya, antara lain :

a. Proses packaging yang digunakan oleh mitra UKM adalah alat siller yang sederhana, hal ini menyebabkan kerupuk singkong (samiler) sulit mengembang saat proses penggorengan dikarenakan adanya udara di dalam kemasan.

b. Penimbangan kerupuk singkong (samiler) oleh mitra UKM menggunakan timbangan pasar/ timbangan bebek. Hal ini menyebabkan adanya berat kerupuk singkong (samiler) saat proses pengemasan tidak valid, sehingga dapat merugikan konsumen dan mitra UKM.

\section{Bidang Pemasaran dan Pengembangan Produk}

Dalam memperkenalkan sebuah produk, maka mitra UKM harus memiliki strategi pemasaran produk agar konsumen memiliki ketertarikan terhadap produk dan usaha yang dilakukan oleh pelaku usaha dapat berkembang dengan baik . Permasalahan yang diidentifikasi pada bidang pemasaran dan pengembangan produk oleh Mitra UKM, antara lain :

\section{a. Kemasan dan Label}

Kemasan produk kerupuk singkong (samiler) yang digunakan oleh Mitra UKM adalah plastik, sedangkan label dibuat dengan cara print pada kertas HVS serta ukuran label adalah $15 \times 10 \mathrm{~cm}$, keterangan kurang lengkap dalam label. Untuk dapat bersaing pada pasar dan mudah diminati oleh masyarakat sebagai konsumen, maka kemasan dan label harus dibuat dengan baik.

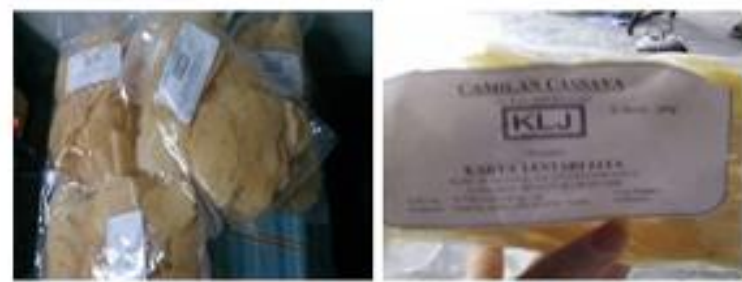

Gambar 2. Kemasan camilan cassava/ kerupuk singkong (samiler)

\section{b. Pengembangan Produk}

Mitra UKM selama ini belum pernah melakukan pengembangan produk. Kerupuk singkong (samiler) selama ini hanyalah kerupuk dengan rasa original saja. Potensi sangat besar jika mitra UKM dapat mengembangkan Kerupuk singkong (samiler) dengan contoh memperbanyak varian rasa pada produknya, sehingga akan mempengaruhi ketertarikan konsumen terhadap kerupuk singkong (samiler).

\section{c. Sistem Pemasaran}

Metode pemasaran yang dilakukan selama ini adalah menempatkan produk opak singkong pada pusat oleh-oleh yang terdapat di daerah Kabupaten Tulungagung, toko toko dan konsumen datang ke lokasi UKM untuk pesan kerupuk singkong (samiler). Penjualan dengan media periklanan internet dan media sosial sangat baik untuk perkembangan jaringan penjualan produk kerupuk singkong (samiler). 


\section{d. Perhitungan Harga Produk}

Mitra UKM Karya Lestari Jaya dalam melakukan perhitungan harga produk per kemasan belum memenuhi standar break even point (BEP), sehingga tidak dapat maksimal dalam pengelolaan usaha.

\section{Metode Kegiatan}

Metode Kegiatan dalam Perbaikan Kemasan Kerupuk Singkong (Samiler) di UKM Karya Lestari Jaya Tulung agung dilakukan dengan beberapa pendekatan dan Tahapan yang dilakukan diantaranya :

1. Tahap Persiapan

Tim Pelaksana dan UKM melakukan koordinasi dengan menentukan kebutuhan Mitra UKM Karya Lestari Jaya terkait dengan peralatan proses produksi serta kebutuhan proses manajemen dan pelatihan. Kegiatan ini juga merencanakan survey kebutuhan alat dan pengadaannya sesuai spesifikasi yang ada. Begitu juga untuk Desain Kemasan maka Kegiatan ini bertujuan untuk merancang desain kemasan yang memiliki standar untuk makanan, sehingga akan meningkatkan permintaan kerupuk singkong.

2. Tahap Pelaksanaan

Kegiatan ini dilakukan untuk melakukan survey beberapa toko yang menjual mesin vaccum sealer dan timbangan digital. Survey yang dilakukan mencakup spesifikasi alat dan kualitas alat, sehingga akan mendapatkan mesin vaccum sealer dan timbangan digital yang sesuai kebutuhan produksi UKM Karya Lestari Jaya.
Selanjutnya dilakukan pemesanan mesin vaccum sealer dan timbangan digital yang sesuai dengan spesifikasi kebutuhan produksi UKM Karya Lestari Jaya.

3. Tahap Pendampingan dan Pelatihan

Pada Tahapan ini dilakukan untuk memberi pengetahuan tentang mesin vaccum sealer dan timbangan digital dari segi mesin, cara pengoperasian dan perawatan mesin kepada mitra UKM dan tenaga kerja. Kegiatan ini juga melakukan pendampingan kepada UKM Karya Lestari Jaya dalam mengembangkan produk. Pengembangan produk dilakukan dengan cara melakukan variasi rasa pada kerupuk singkong (samiler). Kegiatan ini juga untuk memberikan pelatihan dan mendampingi UKM Karya Lestari Jaya dalam menentukan harga produk yang benar (Pelatihan BEP).

4. Tahap Evaluasi

Evaluasi ini dilakukan untuk melihat kemajuan dari penggunaan mesin vaccum sealer dan timbangan digital terhadap proses produksi serta peningkatan proses produksi khususnya dalam hal kemasan dan manajemen pengelolaan.

\section{KaRYA UTAMA}

Dari proses Tahapan yang telah dilakukan oleh Tim Pelaksana dan Mitra UKM Karya Lestari Jaya terkait dengan peralatan proses produksi serta kebutuhan proses manajemen dan pelatihan maka didapatkan Produk Teknologi yang 
digunakan dalam kemsan kerupuk samiler yaitu :

\section{Mesin Vacumm Sealaer dan Timbangan}

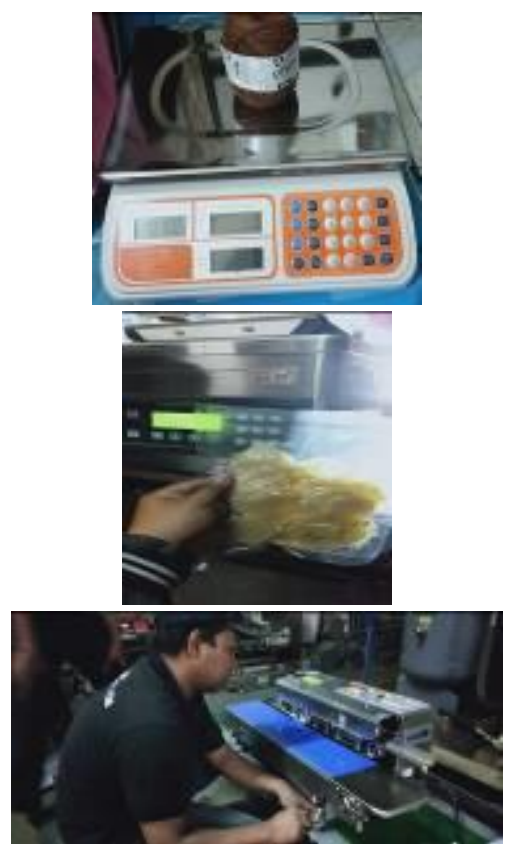

Gambar 3. Mesin Vacumm Sealaer dan Timbangan

\section{Mesin Vacuum Sealer DZ 260}

\section{Spesifikasi :}
a. Tipe : Mini Table Double Dz- 260/PD
b. Listrik : $370 \mathrm{Watt}, 220 \mathrm{~V}, 50 \mathrm{~Hz}$
c. Vacuum Chamber Size : 385 x 280 x $90 \mathrm{~mm}$
d. Min Absolute Pressure : $133 \mathrm{Kpa}$
e. Vaccum Pump Capacity : $10 \mathrm{~m}^{3} / \mathrm{h}$
f. Sealing Size : 250 x $5 \mathrm{~mm}$
g. Dimensi Total Mesin : 330 x 480 x $330 \mathrm{~mm}$
h. Berat Mesin : $35 \mathrm{~kg}$
i. Bahan : full Stainless Steel

\section{Mesin Timbangan Digital 30 kg Spesifikasi :}
a. Merk : Camry
b. Type : ACS-30-JC33
c. Kategori : Timbangan Digital
d. Bahan : Stainless
e. Display Type : LCD
f. Maximum Load : $30 \mathrm{~kg}$
g. Colour : White dan Orange
h. Dimensi : 40 × 37 × $14 \mathrm{~cm}$
i. Power : Adaptor/Bateray

Dari Evaluasi yang dilakukan untuk melihat kemajuan dari penggunaan mesin vaccum sealer dan timbangan digital terhadap proses produksi, seperti pada gambar dibawah 3 diatas menunjukkan bahwa terjadi peningkatan proses produksi khususnya dalam proses pengemasan. Kegiatan pengemasan yang selama ini menggunakan alat pengemasan konvensional mempunyai produktifitas yang rendah. Hal ini dapat diketahui dengan menggunakan alat mesin vaccum sealar dan timbangan digital terjadi peningkatan produksi khususnya waktu produksi. Peningkatan produksi yang dihasilkan sebesar $70 \%$.

\section{Pelatihan Alat}

Dalam permasalahn mitra lainnya yang paling penting adalah juga terkait transfer teknologi dan perhitungan keuntungan yang dihasilkan. ke mitra. Untuk melaksanakan kegiatan tersebut dilakukan Pelatihan Pengoperasian Alat Mesin Vacum sealaer dan Timbangan Digital agar Mitra bisa lebih lancar dalam penggunaan alat sehingga mendungkung peningkatan produksinya. Seperti gambar di bawah ini.

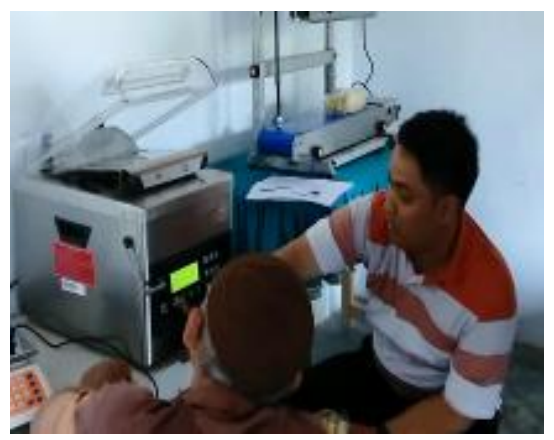




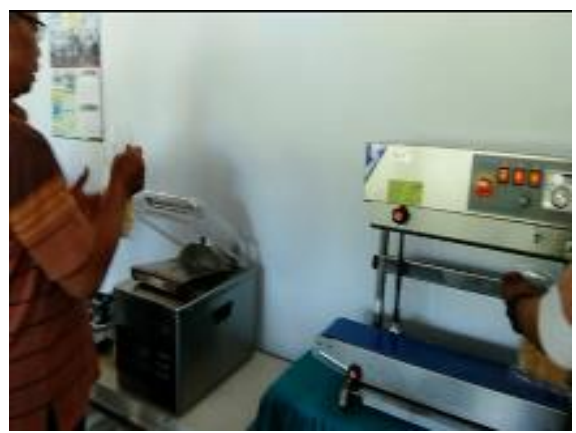

Gambar 4. Pelatihan Alat

\section{Pelatihan BEP dan Hasil Kemasan}

Untuk mengetahui perhitungan produksi kerupuk singkong ini juga perlu diketahui bagaimana Break event point (BEP) dari seluruh proses produksi mulai awal sampai akhir proses produksi sehingga dapat diprediksi berapa keuntungan yang didapat dan berapa lama waktu agar modal yang dikeluarkan kembali seperti semula. Adapun Tujuan dari pelatihan BEP ini adalah :

1. Sebagai alat analisis untuk mengambil kebijakan dalam suatu UKM

2. Mengetahui jumlah penjualan minimal yang harus dipertahankan agar UKM tidak mengalami kerugian

3. Mengetahui jumlah penjualan yang harus dicapai untuk memperoleh tingkat keuntungan tertentu

4. Mengetahui seberapa jauh berkurangnya penjualan

5. Mengetahui bagaimana efek perubahan harga jual, biaya, dan volume penjualan terhadap keuntungan

Dari perhitungan BEP yang dilakukan dengan Variabel-variabel yang ada diantaranya untuk Biaya Tetap Kripik Singkong sebesar Rp. 1.120.400,-, Biaya Variabel Rp. 10.700,-/kg dan Harga Jual sebesar 12.000. Maka Nilai BEP usaha keripik singkong dalam unit sebesar $862 \mathrm{~kg}$ dan jika dinyatakan dalam rupiah sebesar Rp. 10.338.462, 00. Dari hasil penjelasan diatas mitra mendapatkan pemahaman terkait dengan variable-variabel dalam sebuah proses produksi untuk bisa dimasukkan dalam aspek pembiayaan. Hal ini dapat memprediksi sebera besar produksi yang dilakukan dan keuntungan yang didapatkan. Berikut Gambar Pelatihan BEP.

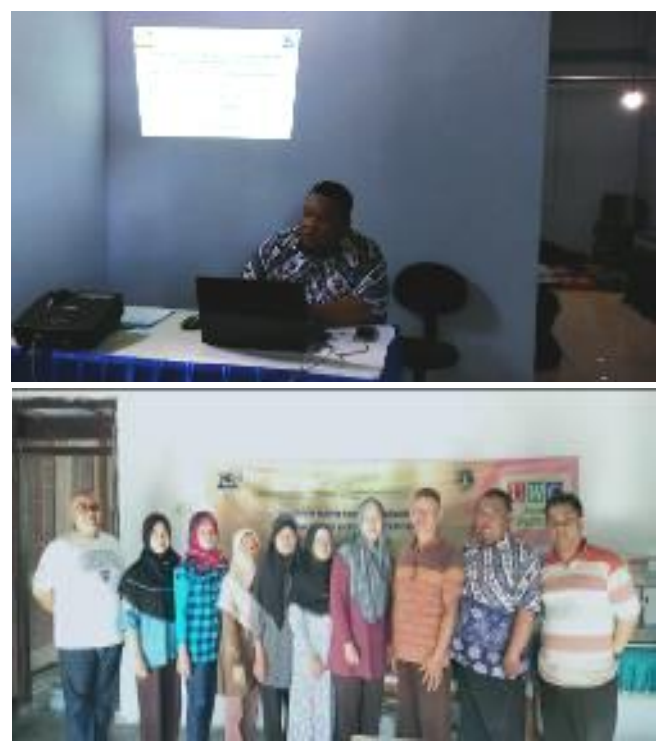

Gambar 5. Pelatihan BEP

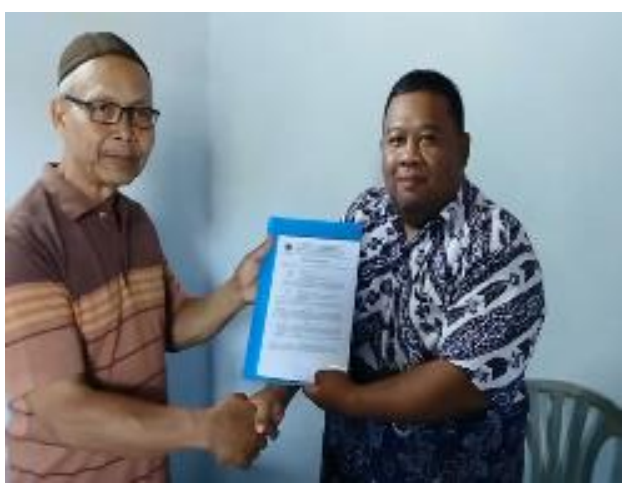






Gambar 6. Serah Terima Barang dan Monev Internal

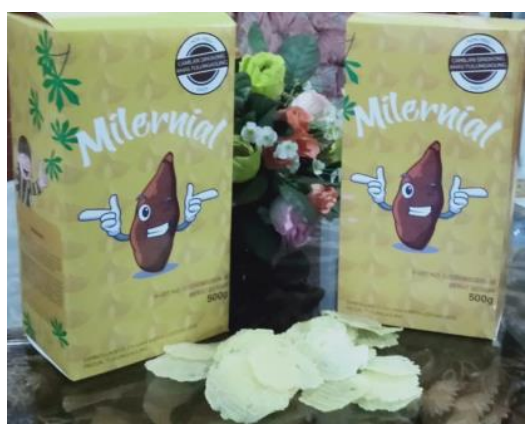

Gambar 7. Hasil Kemasan

\section{Ulasan KaRYA}

Dari hasil wawancara dan proses produksi dengan mitra didapatkan keunggulan dan kelemahan dari kerjasama antara Tim Pengabdian dan Mitra dalam proses peningkatan mutu kemasan keripik singkong (samiler) di UKM Karya Lestari Jaya diantaranya :

1. Dengan adanya teknologi yang diberikan kepada mitra serta pengadaan pelatihan Penggunaan Timbangan Digital dan Mesin Vacuum Selaer dalam proses produksinya meningkatkan waktu produksi sekitar $70 \%$ serta keahlian mitra semakin bertambah dalam penggunaan peralatan berbasis teknologi dibandingkan sebelum menggunakan peralatan konvensional.

2. Kegiatan pelatihan penggunaan alat dan BEP dapat memberikan keuntungan yang lebih baik lagi dikarenakan perencanaan proses produksi yang lebih baik lagi.
3. Kegiatan Evaluasi dilakukan dengan mitra untuk mengetahui tingkat kepuasan dan ketercapaian dari Pelaksana pengabdian yang didapatkkan ketercapaian kegiatan sebesar $100 \%$ dan Mitra merasa puas dengan kerjasamanya.

Adapun untuk kelemahan yang didapatkan adalah bahan baku yang masih kurang banyak dan mencari bahan baku yang kualitasnya baik sangat sulit. Hal ini menghambat peningkatan proses produksi. Begitu juga pemahaman dalam penggunaan alat masih belum terlalu lancar mengakibatkan proses produksinya belum maksimal. Keberlangsungan program pengabdian ini akan semakin baik dengan adanya pendampingan secara berkelanjutan dan konsultatif terkait proses produksi yang dilakukan dan kegiatan-kegiatan lain yang mendukung.

\section{DAMPaK dan ManfaAt Kegiatan}

Program Kemitraan Masyarakat (PKM) di UKM Karya Lestari Jaya mempunyai dampak yang sangat posistif diantaranya Meningkatkan Proses Produksi Kerupuk Singkong, Memberikan Transfer Teknologi terkait alat yang diberikan, meningkatkan kesejahteraan masyarakat sekitar khususnya UKM Karya Lestari Jaya. Adapun manfaat yang didapatkan adalah Gairah UKM khusunya Kerupuk Singkong di Desa Mitra bisa lebih baik lagi dan menjadi Sentra Kerupuk Singkong di Kota mitra serta menarik investor untuk memberikan investasinya agar menjadi berkembang lebih baik lagi.

\section{Kesimpulan}

Dari proses pengabdian pada masyarakat yang dilakukan di UKM 
Karya Lestari Jaya terhadap produk keripik singkong (samiler) didapatkan kesimpulan diantaranya :

1. Dalam kegitan Pengabdian kepada UKM ini sudah melakukan tahapantahpan yang direncanakan diantaranya Pengadaan Teknologi Pengemasan, Pelatihan Penggunaan Alat, Pelatihan BEP dan Pembuatan Produk Kemasan baru serta melakukan evaluasi secara keseluruhan. Adapun tingkat ketercapaian dari tahapan yang dilaksanakan sebesar $100 \%$. Hal ini ditunjukkan dengan kegiatan yang dilaksanakan lengkap serta kepuasan mitra terhadap proses pengabdian ini.

2. Dengan menggunakan Mesin Vacuum Sealer dan Timbangan Digital meningkatkan produksi keripik singkong sampai dengan $70 \%$.

3. Dengan dilakukan pelatihan penggunaan alat dan BEP menambah ilmu yang didapatkan sehingga bisa meningkatkan waktu produksi dan merencanakan proses produksi kerupuk lebih baik serta memberikan penambahan keuntungan.

4. Saran dari pengabdian ini adalah perlu dilakukan proses pendampingan secara berkelanjutan untuk peningkatan produksi, pengembangan jenis-jenis produk dan memastikan ketersediaan bahan baku serta perawatan alat yang telah digunakan.

\section{PENGHARGAAN}

Kami dari Tim Pengabdian mengucapkan Banyak Terima Kasih kepada DRPM Kemenristekdikti yang telah memberikan dana hibah pengabdian pelaksanaan tahun 2019, LPPM Universitas Widyagama Malang yang selalu mensupport, UKM Karya Lestari Jaya sebagai Mitra Kami. Semoga kerjasama ini berjalan secara berkelanjutan dan bermanfaat bagi kita semua.

\section{DAFTAR PUSTAKA}

[1]. Prabawati, S., Richana, N. and Suismono, 2011. Inovasi Pengolahan Singkong Meningkatkan Pendapatan dan Diversifikasi Pangan. Sinar Tani Edisi 4-10 Mei 2011 No.3404 Tahun $X L I,(4), \mathrm{pp} .1-5$

[2]. BPS JATIM, 2018. Produksi Ubi Kayu Menurut Kabupaten / Kota di Jawa Timur (ton), 2007-2016. [online] Available at: <https://jatim.bps.go.id/statictable/20 18/02/07/870/produksi-ubi-kayumenurut-kabupaten-kota-di-jawatimur-ton-2007-2016.html> [Accessed 21 Aug. 2018].

[3]. Asnidar and Asrida, 2017. Analisis Kelayakan Usaha Home Industry Kerupuk Opak Di Desa Paloh Meunasah Dayah Kecamatan Muara Satu Kabupaten Aceh Utara. Jurnal S. Pertanian, 1(1), pp.39-47. 